\title{
Influence of Meteorological Factors on the Potential Evapotranspiration in Yanhe River Basin, China
}

\author{
Yu Luo ${ }^{1,2}$, Peng Gao ${ }^{1,2,3, *}$ and Xingmin Mu ${ }^{1,2,3, *}$ \\ 1 State Key Laboratory of Soil Erosion and Dryland Agriculture on Loess Plateau, Institute of Soil and Water \\ Conservation, Chinese Academy of Sciences and Ministry of Water Resources, Yangling, Shaanxi 712100, \\ China; luoyu18@mails.ucas.ac.cn \\ 2 University of Chinese Academy of Sciences, Beijing 100000, China \\ 3 State Key Laboratory of Soil Erosion and Dryland Agriculture on Loess Plateau, Northwest A \& F University, \\ Yangling, Shaanxi 712100, China \\ * Correspondence: gaopeng@ms.iswc.ac.cn (P.G.); xmmu@ms.iswc.ac.cn (X.M.); \\ Tel.: +86-29-8701-2875 (P.G.); +86-29-8701-2411 (X.M.)
}

Citation: Luo, Y.; Gao, P.; Mu, X. Influence of Meteorological Factors on the Potential Evapotranspiration in Yanhe River Basin, China. Water 2021, 13, 1222.

https://doi.org/10.3390

/w13091222

Academic Editor: Maria Mimikou

Received: 9 April 2021

Accepted: 24 April 2021

Published: 28 April 2021

Publisher's Note: MDPI stays neutral with regard to jurisdictional claims in published maps and institutional affiliations.

Copyright: (c) 2021 by the authors. Licensee MDPI, Basel, Switzerland. This article is an open access article distributed under the terms and conditions of the Creative Commons Attribution (CC BY) license (https:/ / creativecommons.org/licenses/by/ $4.0 /)$.

\begin{abstract}
Potential evapotranspiration $\left(E T_{0}\right)$ is an essential component of the hydrological cycle, and quantitative estimation of the influence of meteorological factors on $E T_{0}$ can provide a scientific basis for studying the impact mechanisms of climate change. In the present research, the Penman-Monteith method was used to calculate $E T_{0}$. The Mann-Kendall statistical test with the inverse distance weighting were used to analyze the spatiotemporal characteristics of the sensitivity coefficients and contribution rates of meteorological factors to $E T_{0}$ to identify the mechanisms underlying changing $E T_{0}$ rates. The results showed that the average $E T_{0}$ for the Yanhe River Basin, China from 1978-2017 was $935.92 \mathrm{~mm}$. Save for a single location (Ganquan), ET 0 increased over the study period. Generally, the sensitivity coefficients of air temperature (0.08), wind speed at $2 \mathrm{~m}(0.19)$, and solar radiation $(0.42)$ were positive, while that of relative humidity was negative $(-0.41)$, although significant spatiotemporal differences were observed. Increasing air temperature and solar radiation contributed $1.09 \%$ and $0.55 \%$ of the observed rising $E T_{0}$ rates, respectively; whereas decreasing wind speed contributed $-0.63 \%$, and relative humidity accounted for $-0.85 \%$. Therefore, it was concluded that the decrease of relative humidity did not cause the observed $E T_{0}$ increase in the basin. The predominant factor driving increasing $E T_{0}$ was rising air temperatures, but this too varied significantly by location and time (intra- and interannually). Decreasing wind speed at Ganquan Station decreased $E T_{0}$ by $-9.16 \%$, and was the primary factor underlying the observed, local "evaporation paradox". Generally, increase in $E T_{0}$ was driven by air temperature, wind speed and solar radiation, whereas decrease was derived from relative humidity.
\end{abstract}

Keywords: climate change; changing meteorological factors; potential evapotranspiration; sensitivity coefficient; contribution rate; dominant factor

\section{Introduction}

According to the sixth report of the IPCC(Intergovernmental Panel on Climate Change) [1], the increase in global mean surface temperature has reached $0.87^{\circ} \mathrm{C}$ in $2006-2015$. Warming temperatures intensify hydrological cycling and affect the spatiotemporal allocation of water resources, increasing the frequency and intensity of water-related disasters [2] and posing challenges to people's safety, socioeconomic development, and environmental security. Therefore, hydrological research is of utmost importance.

Evapotranspiration (ET), composed of water evaporation and transpiration from the surface, water, and plants, is an essential component of the water cycle, with corresponding control over the balances of water and energy. In practical applications, the concepts are divided into actual and potential $\left(E T_{0}\right)$, where the former refers to ET under the true conditions of the surface, and latter describes ET levels when the surface is theoretically 
supplied with limitless water [3]. $E T_{0}$ represents the limit value of actual ET in a region [4], determines the dry and wet condition of a basin, and is an important indicator for estimating basin ET capacity [2]. Although ET under warming climates has been increasing in some regions, such as western Africa [5], Israel [6], and southern China [7], $E T_{0}$ is largely decreasing around the globe in a phenomenon known as the "evaporation paradox" [8-11]. Scholars exploring the causes of changes in $E T_{0}$ have found that the decline in $E T_{0}$ in Australia [8], Iran [12], and southern Canada [10] were mainly caused by wind speed; whereas a decline in $E T_{0}$ in India was most closely related to relative humidity [13]. In China, the most critical factor linked to the decline of $E T_{0}$ is water vapor pressure [14]; however, due to the large geographical differentiation of natural conditions across the diverse regions of China, the drivers of $E T_{0}$ display significant spatial heterogeneity. $E T_{0}$ of the Yellow River Basin has been increasing, with patterns most closely associated with air temperature, followed by incoming solar radiation [15]. The most important meteorological factor for $E T_{0}$ in the Yangtze River Basin was relative humidity [16], but decreases in solar radiation and wind speed were the main factors influencing lowered levels of $E T_{0}$ [17]. ET in the upper reaches of the Heihe River Basin was also most correlated to relative humidity, but the observed changes were mainly driven by wind speed [18]. The observed decrease of $E T_{0}$ on the Qinghai-Tibet Plateau was related to a decrease of wind speed as well, in addition to a decrease in net radiation, and increase in air temperature [19]. The increasing $E T_{0}$ of the Loess Plateau was caused by the combined effect of rising air temperatures and declining in relative humidity, wind speed, and sunshine hours [20]. As indicated by the varied response of $E T_{0}$ to the complexities of the changing climate across spatially heterogeneous areas, the precise influence of climate factors on $E T_{0}$ are still highly uncertain and deserving of further exploration. Further, Liu et al. [21] found that the change of $E T_{0}$ was not only affected by the climate sensitivity coefficient but is also related to the changing trend of meteorological factors. Thus, only by combining the sensitivity coefficient and contribution rate can we systematically and quantitatively analyze the driving mechanisms of change for $E T_{0}$ [22].

Since the 1990s, climate change and anthropogenic activity have had a pronounced impact on the hydrological cycle of the Loess Plateau. The Yanhe River Basin (YRB), a typical watershed in the hilly and gully region of the Loess Plateau, provides an optimal opportunity for a more in-depth understanding of the impacts of climate change on $E T_{0}$ in a region of great significance for understanding the allocation of water resources and components of the water cycle for the region. Therefore, the YRB was selected as the study area for the present research. The Penman-Monteith method was used to calculate $E T_{0}$, with the objectives of analyzing sensitivity to four major meteorological variables and changing trends of various climate factors. Subsequently, the contribution of these factors were quantitatively estimated, so as to reveal the mechanisms of observed $E T_{0}$ changes in the YRB over the past 40 years. Broadly, this study contributes to a more thorough understanding of the impact mechanisms of climate change on the hydrological cycle and provides a scientific basis for water resource evaluation and management, in addition to informing agricultural planting structures.

\section{Data and Methods}

\subsection{Study Area}

The YRB is a first-level tributary of the middle reaches of the Yellow River, extending $286.9 \mathrm{~km}$ over a total drainage area of $7725 \mathrm{~km}^{2}$. It originates from Zhoushan, Tianciwan Township, Jingbian County, and proceeds to flow through four primary counties and cities-Zhidan, Ansai, Baota, and Yanchang - and enters the Yellow River near the bank of Nanhegou Township in Yanchang County. The YRB maintains a continental monsoon climate, which is dry-windy in spring, warm-rainy in summer, cool-rainy in autumn, and cold-dry in the winter [23]. Average annual levels are: precipitation, about $520 \mathrm{~mm}$; air temperature, $8.8-10.2{ }^{\circ} \mathrm{C}$; evaporation $898-1678 \mathrm{~mm}$; and sunshine duration, $2450 \mathrm{~h}$ [24]. 


\subsection{Data}

The meteorological data in the present study were acquired from China Meteorological Data Network (http: / / data.cma.cn/ (accessed on 20 June 2020)), and included the daily average, maximum, and minimum air temperatures $\left(T, T_{\max }\right.$, and $T_{\min }$, respectively), wind speed at $10 \mathrm{~m}\left(U_{10}\right)$, sunshine duration $(n$, in $\mathrm{h})$, daily average relative humidity $(R H)$, and the daily precipitation $(P)$. The $U_{10}$ was converted into wind speed of $2 \mathrm{~m}\left(U_{2}\right)$ by $U_{2}=0.75 \cdot U_{10}$. Data were collected across a time series from 1978-2017, derived from the specific control hydrological station of Ganguyi, and meteorological stations in Jingbian, Wuqi, Zhidan, Ansai, Yan'an, Zichang, Yanchuan, Yanchang, Ganquan and Yichuan (Figure 1).

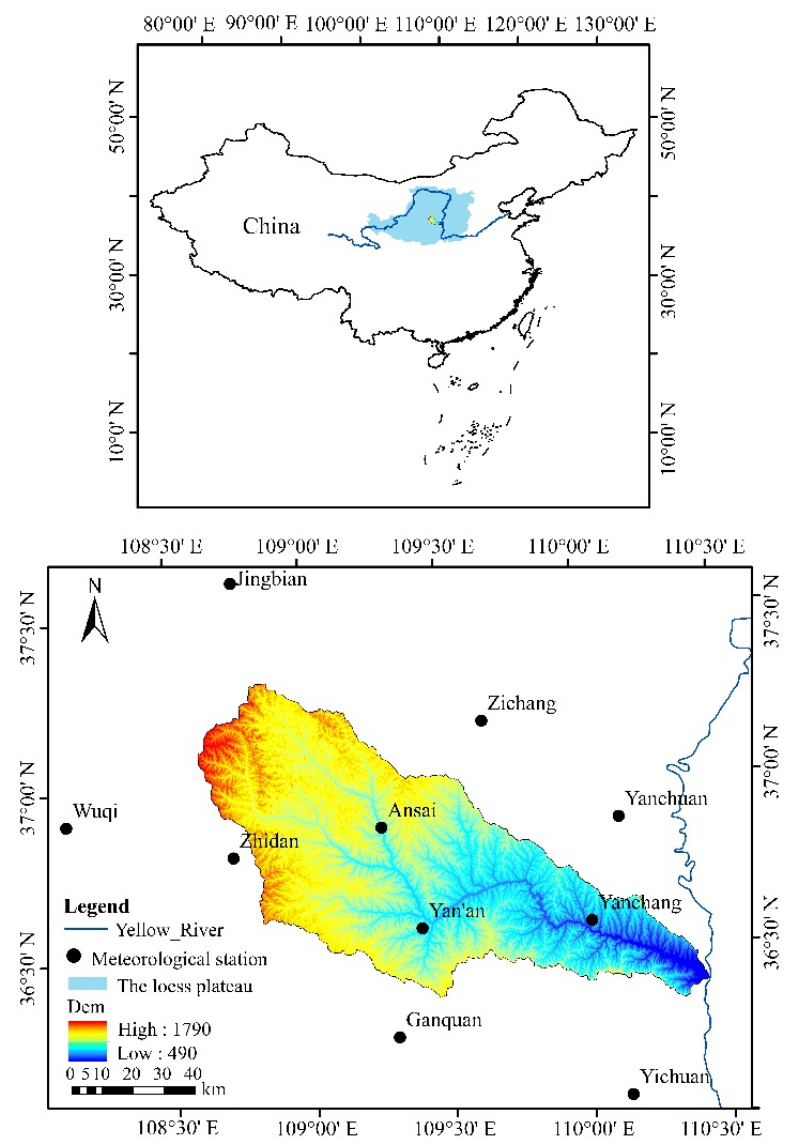

Figure 1. Location of the Yanhe River Basin and the meteorological stations used in this study (black dots).

\section{3. $E T_{0}$}

The Penman-Monteith method, a commonly accepted standard in the literature, was used in the present research to calculate $E T_{0}$ (Equation (1)) [25]:

$$
E T_{0}=\frac{0.408 \Delta\left(R_{n}-G\right)+\gamma \frac{900}{(T+273)} U_{2}\left(e_{s}-e_{a}\right)}{\Delta+\gamma\left(1+0.34 U_{2}\right)}
$$

where $E T_{0}$ is potential evapotranspiration $(\mathrm{mm}) ; R_{n}$ is the net radiation $\left(\mathrm{MJ} \cdot \mathrm{mm}^{-2} \cdot \mathrm{day}^{-1}\right)$; $G$ is the soil heat flux $\left(\mathrm{MJ} \cdot \mathrm{mm}^{-2} \cdot \mathrm{day}^{-1}\right) ; \gamma$ is the psychrometric constant $\left(\mathrm{kPa} \cdot{ }^{\circ} \mathrm{C}^{-1}\right) ; T$ is mean daily air temperature $\left({ }^{\circ} \mathrm{C}\right) ; U_{2}$ is the wind speed at $2 \mathrm{~m}$ height $\left(\mathrm{m} \cdot \mathrm{s}^{-1}\right) ; e_{s}$ and $e_{a}$ are saturation and actual vapor pressure $(\mathrm{kPa})$, respectively; and $\Delta$ is the slope of the vapor pressure curve $\left(\mathrm{kPa} \cdot{ }^{\circ} \mathrm{C}^{-1}\right)$. 


\subsection{Calculation of Sensitivity Coefficient}

The dimensionless sensitivity coefficient $S_{i}$ [26-29] was used to characterize the sensitivity of $E T_{0}$ to climate change. This method analyzes the impact of a single climatic factor on $E T_{0}$, while holding all others constant, and is calculated according to Equation (2):

$$
S_{i}=\frac{\partial E T_{0}}{\partial i} \frac{i}{E T_{0}}
$$

where $i$ is change in the climate factor being assessed, and $\partial E T_{0} / \partial i$ is the partial derivative of $E T_{0}$ with respect to climate factor $i$.

A positive (negative) sensitivity coefficient indicates that $E T_{0}$ will increase (decrease) as the variable increases; and the absolute value of the sensitivity coefficient indicates the climatic factor's degree of influence. An $S_{i}$ of -0.1 , for example, indicates that a $10 \%$ increase (decrease) of factor $i$ will cause a $5 \%$ decrease (increase) in $E T_{0}$ when the other meteorological variables are held constant. In the present study, the sensitivity coefficients of average air temperature, humidity, wind speed, and solar radiation were calculated and denoted as $S_{T}, S_{R H}, S_{U_{2}}, S_{R_{S}}$, respectively. In this study, we regarded March to May as spring, June to August as summer, September to November as autumn and December to February as winter. Further, the monthly and annual values of the sensitivity coefficients were obtained by averaging the daily sensitivity coefficients.

\subsection{Calculation of Contribution Rate}

In the research here, the contribution rate of climatic factors to $E T_{0}$ was indicated by multiplying $S_{i}$ by the relative change rate of factor $i$ [7], and computed according to Equations (3) and (4).

$$
\begin{gathered}
C_{i}=S_{i} \cdot R_{i} \\
R_{i}=\frac{N \cdot L_{i}}{M_{i}} 100 \%
\end{gathered}
$$

where $C_{i}$ is the contribution rate of change of $i$ to $E T_{0}(\%), R_{i}$ is the relative rate of change of climatic factor $i, N$ is the number of years in the study period, $L_{i}$ is the linear trend rate of climatic factor $i$, and $M_{i}$ is the average value of the climatic factor.

Similarly to $S_{i}$, positive (negative) $C_{i}$ indicates the positive (negative) effect of climatic factor $i$ on the change of $E T_{0}$, and the greater its absolute value, the greater its contribution.

\subsection{Analytical Method}

The non-parametric Mann-Kendall statistical test $[30,31]$ was used to detect the trends of the sensitivity coefficients, and resulting contribution rates of $E T_{0}$ in the YRB from 1978 to 2017. The inverse distance weighting method was used to further interpolate the sensitivity coefficient and contribution rate [32].

\section{Results}

\subsection{Temporal and Spatial Characteristics of $E T_{0}$ and Meteorological Factors}

The changes in multi-year average monthly $E T_{0}$ and meteorological factors for the YRB are shown in Table 1. Averages from 1978-2017 were: air temperature, $9.59{ }^{\circ} \mathrm{C}$ (maximum observed from June to August); RH, 60.05\% (maximum observed from August to October); wind speed at $2 \mathrm{~m}$ height, $1.16 \mathrm{~m} \cdot \mathrm{s}^{-1}$ (maximum observed from March to May); solar radiation, $5645.81 \mathrm{MJ} \cdot \mathrm{mm}^{-2}$. day ${ }^{-1}$ (maximum observed from May to July); and precipitation, $495.19 \mathrm{~mm}$ (maximum observed from July to September). The results of the Mann-Kendall statistical test indicated that air temperature $(p<0.01)$, solar radiation, and precipitation showed an increasing trend with time, while $R H$ and wind speed at $2 \mathrm{~m}$ height were decreasing. The average ET of YRB was $935.92 \mathrm{~mm}$, peaking from May to July. Overall, $E T_{0}$ showed an increasing trend $(p<0.1)$, while $E T_{0}$ values for September-October were decreasing, although not at a statistically significant level. 
Table 1. Temporal characteristics of $E T_{0}$ and meteorological factors in Yanhe River Basin.

\begin{tabular}{|c|c|c|c|c|c|c|c|c|c|c|c|c|}
\hline \multirow[b]{2}{*}{ Time } & \multicolumn{6}{|c|}{ Mean } & \multicolumn{6}{|c|}{ M-K Statistics } \\
\hline & $T /{ }^{\circ} \mathrm{C}$ & $R H / \%$ & $U_{2} /\left(\mathrm{m} \mathrm{s}^{-1}\right)$ & $\begin{array}{c}R s /\left(\mathrm{MJ} \mathrm{mm}^{-2}\right. \\
\left.\text { Day }^{-1}\right)\end{array}$ & $P / \mathrm{mm}$ & $E T_{0} /(\mathrm{mm})$ & $T$ & $R H$ & $U_{2}$ & $R s$ & $P$ & $E T_{0}$ \\
\hline Jan. & -6.07 & 53.85 & 1.03 & 304.92 & 3.00 & 23.37 & 1.68 & 0.72 & 0.93 & 0.51 & 0.63 & 0.49 \\
\hline Feb. & -2.05 & 52.44 & 1.13 & 336.89 & 5.65 & 33.90 & 2.73 & 1.1 & -0.09 & 0.61 & 2.14 & 1.7 \\
\hline Mar. & 4.33 & 50.53 & 1.32 & 478.71 & 14.28 & 66.43 & 3.12 & -2.31 & -0.19 & 2.42 & -2.33 & 3.36 \\
\hline Apr. & 11.76 & 46.48 & 1.48 & 580.06 & 24.05 & 104.39 & 2.24 & -0.47 & -3.03 & 1.44 & 1.07 & 0.49 \\
\hline May. & 17.20 & 50.93 & 1.40 & 664.94 & 43.40 & 133.22 & 0.75 & -0.37 & -2.07 & 1 & 0.54 & 0.28 \\
\hline Jun. & 21.29 & 57.66 & 1.26 & 655.36 & 60.54 & 139.72 & 1.68 & -1.17 & -0.93 & 0.93 & -1.1 & 1 \\
\hline Jul. & 22.99 & 69.01 & 1.11 & 631.68 & 115.24 & 134.55 & 2.63 & -1.24 & 0.72 & 0.72 & 0.3 & 1.63 \\
\hline Aug. & 21.24 & 74.17 & 1.03 & 573.99 & 107.19 & 114.22 & 1.7 & -2.21 & 1.12 & -0.42 & -1 & 0.7 \\
\hline Sep. & 16.04 & 74.92 & 0.98 & 453.95 & 71.85 & 78.29 & 2.82 & -0.21 & 1.84 & -1.86 & 0.98 & -0.49 \\
\hline Oct. & 9.63 & 70.20 & 1.02 & 384.49 & 34.76 & 53.65 & 1.61 & 1.26 & 0.05 & -1.05 & 0.72 & -0.21 \\
\hline Nov. & 2.22 & 62.64 & 1.07 & 304.19 & 12.64 & 32.13 & 1.98 & -0.19 & -0.23 & -0.02 & -0.3 & 0.68 \\
\hline Dec. & -4.23 & 57.03 & 1.04 & 276.63 & 2.60 & 22.07 & 0.89 & -0.68 & 1.35 & 0.63 & 0.56 & 0.96 \\
\hline Year & 9.59 & 60.05 & 1.16 & 5645.81 & 495.19 & 935.92 & 3.8 & -1.12 & -0.7 & 0.56 & 0.42 & 1.65 \\
\hline
\end{tabular}

Average annual air temperature of YRB from 1978 to 2017 presented a geographical distribution pattern of southeastern highs and northwestern lows, both of which increased over time (Figure 2). RH displayed highs in the west and east, and lows in the north and south. Only the Zichang and Yanchang stations showed an insignificant rising trend in $\mathrm{RH}$, indicating that the YRB underwent significant warming and drying. $U_{2}$ reached lows in the east and west, highs to the north and south, with an overall downward trend save for the Zichang, Yanchang, Yanchuan, and Yichuan stations showing an increase. The incoming solar radiation in the southeast was less than that in the south, and displayed a decreasing trend; whereas the solar radiation at Yan'an and Jingbian stations were the highest in the basin, showing an upward trend. Precipitation in the YRB had a distribution pattern of south $>$ southeast $>$ northwest, peaking at Yan'an and Ganquan stations. Save for the sole location of Yan'an, precipitation in the basin showed an upward trend. $E T_{0}$ was greatest in the south and least in the west. An upward trend was observed for all sites except Ganquan, where decreasing $E T_{0}$ levels with increasing air temperature indicated the local existence of the "evaporation paradox" phenomenon. It can be seen that the intra-annual characteristics of meteorological factors and $E T_{0}$ were variable, and spatial heterogeneity was significant throughout the study region.

\subsection{Sensitivity of $E T_{0}$ to Meteorological Factors \\ 3.2.1. Temporal Characteristics}

$S_{T}, S_{R H}$, and $S_{R_{S}}$ showed an intra-annual, single peak pattern, indicating that $E T_{0}$ was more sensitive to temperature conditions and sunshine duration in the summer over this scale. In addition, $S_{U_{2}}$ showed a unimodal distribution, displaying that $E T_{0}$ was most sensitive to wind speed in the winter (Figure 3). On an interannual scale, $S_{T}, S_{R_{S}}$, and $S_{U_{2}}$ increased, whereas $S_{R H}$ decreased. The absolute value of $S_{R_{S}}(0.42)$ was the largest of the factors examined, indicating that $E T_{0}$ was most sensitive to solar radiation, and increased by $4.2 \%$ for every $10 \%$ increase in solar radiation (while holding all other factors constant; Table 2). Examining each month across all years, $S_{T}$ was positive except for in the winter, $S_{R H}$ was consistently negative, $S_{U_{2}}$ was positive throughout, and $S_{R_{S}}$ was positive except for December. From analyses of the absolute values for the sensitivity coefficients of $E T_{0}$, it was revealed that spring-summer values were mainly affected by solar radiation, and autumn-winter values by $R H$. Examining the $\mathrm{M}-\mathrm{K}$ statistics, the monthly sensitivity coefficients of $E T_{0}$ in the YRB were variable: $S_{T}$ increased over the study period, but declined in the months from March-September (save for April); $S_{R H}$ decreased annually, but increased within each year from March-June; $S_{U_{2}}$ increased overall, but decreased in the month of October; and $S_{R_{S}}$ mostly decreased annually, but increased each year in 
April and May. It was found that over the 40-year study period, the sensitivity of $E T_{0}$ to air temperature and wind speed had increased, while sensitivity to solar radiation and $R H$ decreased. The sensitivity of $E T_{0}$ to the climatic factors examined varied by month throughout the year, and within each month of the year as well.

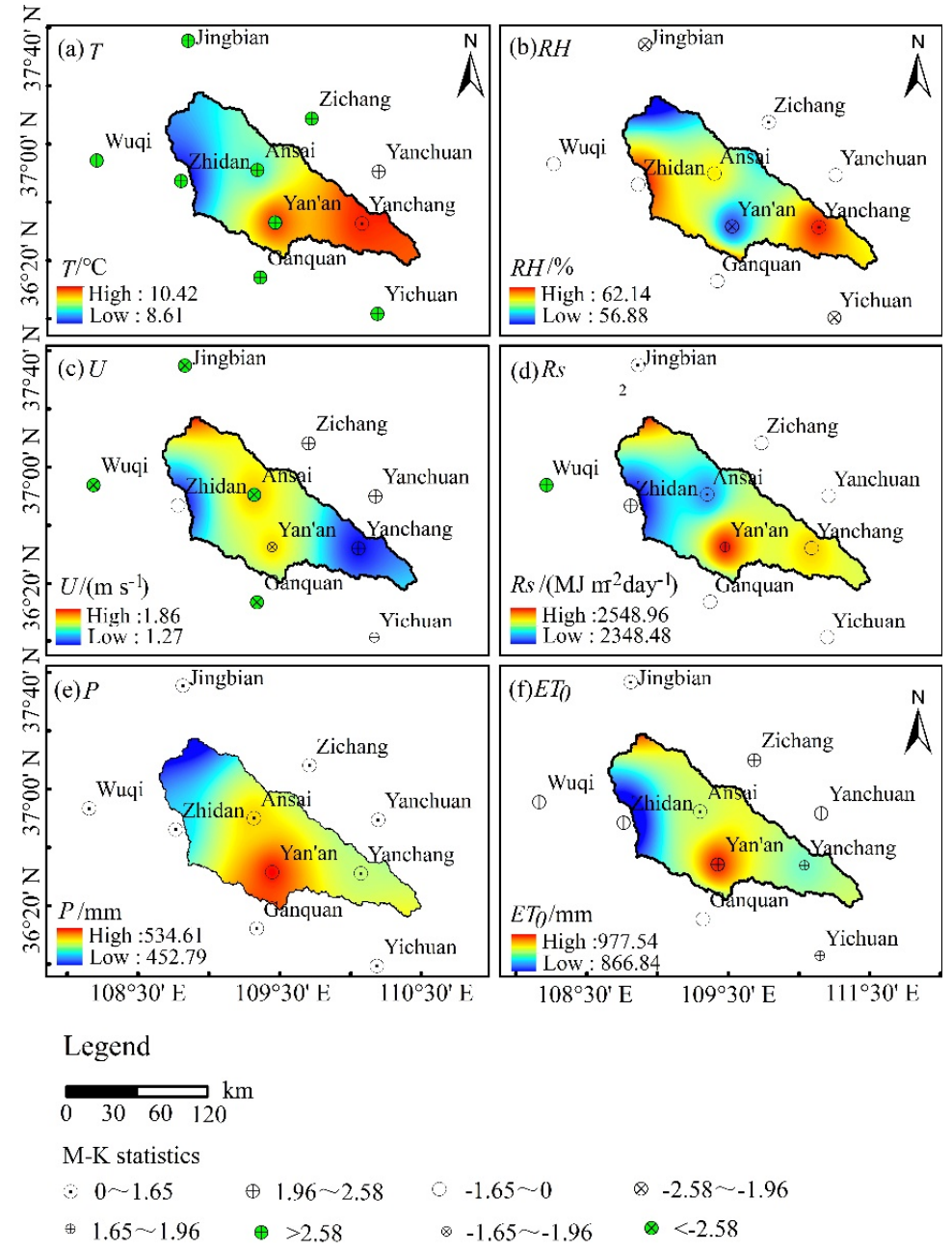

Figure 2. Spatial distribution of factors: (a) air temperature, (b) humidity, (c) wind speed at $2 \mathrm{~m}$ height, (d) solar radiation, (e) precipitation, and (f) the potential evapotranspiration.

\subsubsection{Spatial Characteristics}

$S_{T}, S_{U_{2}}$, and $S_{R_{S}}$ at each site in the YRB were positive values, whereas $S_{R H}$ was the sole factor with a negative value. The absolute values of $S_{R H}$ at the Jingbian, Zichang, Ansai, Yan'an, Ganquan, and Yichuan stations were the largest of all factors, indicating the importance of $R H$ when determining $E T_{0}$. The absolute values of $S_{R s}$ at the Wuqi, Zhidan, Yanchuan, and Yanchang stations were larger than elsewhere, confirming the importance of solar radiation on $E T_{0} . S_{T}$ tended to increase across all stations, save for Yan'an, Yanchang, and Yichuan; whereas $S_{R H}$ tended to decrease save for Jingbian, Wuqi, Yan'an, and Ganquan stations. Except for Wuqi station, sensitivity of $S_{U_{2}}$ was increasing. $S_{R_{S}}$ was increased only at Ansai, Ganquan, and Wuqi stations, while decreasing at all other sites (Table 3). Therefore, the $E T_{0}$ of the YRB was most sensitive to $R H$ and solar radiation, but this influence appears to be weakening. Contrarily, the sensitivity of $E T_{0}$ to air temperature and wind speed was small, but sensitivity is increasing. 


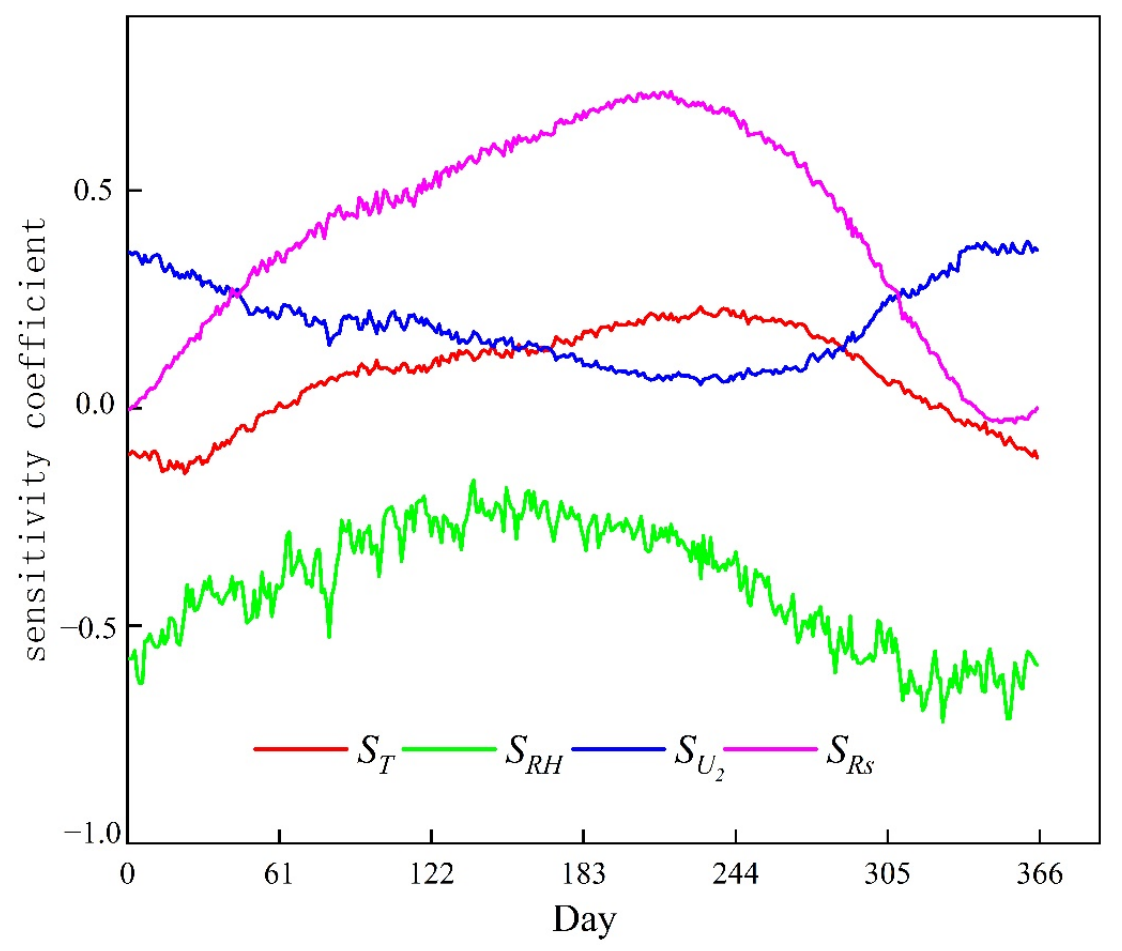

Figure 3. Characteristics of average daily sensitivity coefficient of $E T_{0}$ to meteorological factors.

Table 2. Temporal characteristics of sensitivity coefficient of $E T_{0}$ to meteorological factors.

\begin{tabular}{ccccccccc}
\hline \multirow{2}{*}{ Time } & \multicolumn{4}{c}{ Mean } & \multicolumn{5}{c}{ M-K Statistics } \\
\cline { 2 - 8 } & $S_{T}$ & $S_{R H}$ & $S_{U 2}$ & $S_{R s}$ & $S_{T}$ & $S_{R H}$ & $S_{U 2}$ & $S_{R s}$ \\
\hline Jan. & -0.12 & -0.51 & 0.32 & 0.09 & 1.33 & -2.31 & 1.35 & -0.56 \\
Feb. & -0.05 & -0.43 & 0.25 & 0.27 & 2.10 & -1.77 & 0.56 & -0.58 \\
Mar. & 0.04 & -0.36 & 0.20 & 0.40 & -0.33 & 1.82 & 2.82 & -2.21 \\
Apr. & 0.09 & -0.28 & 0.20 & 0.48 & 0.19 & 0.89 & 0.16 & 1.12 \\
May. & 0.12 & -0.25 & 0.16 & 0.56 & -0.19 & 1.07 & 0.30 & 0.09 \\
Jun. & 0.14 & -0.24 & 0.13 & 0.63 & -0.89 & 1.24 & 0.93 & -0.07 \\
Jul. & 0.19 & -0.28 & 0.09 & 0.70 & -1.98 & -0.02 & 1.70 & -1.07 \\
Aug. & 0.22 & -0.33 & 0.07 & 0.70 & -2.54 & -1.37 & 2.63 & -2.83 \\
Sep. & 0.20 & -0.44 & 0.09 & 0.61 & -1.33 & -2.77 & 1.37 & -2.38 \\
Oct. & 0.13 & -0.54 & 0.16 & 0.43 & 0.61 & -1.82 & -0.42 & -0.37 \\
Nov. & 0.02 & -0.62 & 0.29 & 0.16 & 1.00 & -0.91 & 1.12 & -1.19 \\
Dec. & -0.07 & -0.61 & 0.37 & -0.01 & 2.84 & -0.93 & 1.40 & -1.21 \\
Year & 0.08 & -0.41 & 0.19 & 0.42 & 0.82 & -1.51 & 2.80 & -1.82 \\
\hline
\end{tabular}

Table 3. M-K statistics of Sensitivity coefficient of $E T_{0}$ to meteorological factors of Yanhe River Basin.

\begin{tabular}{ccccccccc}
\hline \multirow{2}{*}{ Station } & \multicolumn{4}{c}{ Mean } & \multicolumn{5}{c}{ M-K Statistics } \\
\cline { 2 - 9 } & $S_{\boldsymbol{T}}$ & $S_{\boldsymbol{R H}}$ & $S_{\boldsymbol{U} \mathbf{2}}$ & $S_{\boldsymbol{R} s}$ & $S_{\boldsymbol{T}}$ & $\boldsymbol{S}_{\boldsymbol{R} \boldsymbol{H}}$ & $\boldsymbol{S}_{\boldsymbol{U} \mathbf{2}}$ & $\boldsymbol{S}_{\boldsymbol{R} \boldsymbol{s}}$ \\
\hline Jingbian & 0.03 & -0.46 & 0.26 & 0.34 & 1.12 & 3.05 & 2.89 & -0.40 \\
Wuqi & 0.07 & -0.36 & 0.17 & 0.43 & 0.56 & 2.07 & -0.07 & 1.54 \\
Zichang & 0.07 & -0.43 & 0.21 & 0.40 & 0.51 & -3.57 & 1.42 & -1.30 \\
Zhidan & 0.08 & -0.34 & 0.16 & 0.45 & 2.77 & -1.21 & 2.10 & -0.77 \\
Ansai & 0.08 & -0.45 & 0.20 & 0.41 & 1.26 & -0.16 & 1.07 & 0.72 \\
Yan'an & 0.08 & -0.44 & 0.21 & 0.41 & -1.56 & 0.05 & 1.33 & -1.30 \\
Ganquan & 0.09 & -0.46 & 0.17 & 0.45 & 2.68 & 3.38 & 0.54 & 1.72 \\
Yanchuan & 0.08 & -0.28 & 0.17 & 0.44 & 0.61 & -2.68 & 4.24 & -3.36 \\
Yanchang & 0.10 & -0.39 & 0.18 & 0.45 & -1.72 & -2.96 & 3.36 & -3.22 \\
Yichuan & 0.09 & -0.45 & 0.20 & 0.42 & -1.56 & -2.49 & 3.61 & -3.84 \\
\hline
\end{tabular}


The geographic distribution of $E T_{0}$ sensitivity to climatic factors was derived by spatial interpolation of the sensitivity coefficients for each station (Figure 4): $S_{T}$ gradually decreased from SE to NW of the basin, peaking in the Yanchang area; $S_{R H}$ increased from the central to SE and SW of the basin, reaching its maximum in Zhidan and Yanchuan, respectively; $S_{U_{2}}$ was roughly opposite of $S_{R H}$, with a minimum in the Zhidan area; the distribution pattern of $S_{R_{S}}$ was similar to that of $S_{R H}$, reaching maximums in Zhidan, Ganquan, and Yanchang. Thus, the sensitivity of $E T_{0}$ to each climate factor analyzed varied significantly by geographic location.

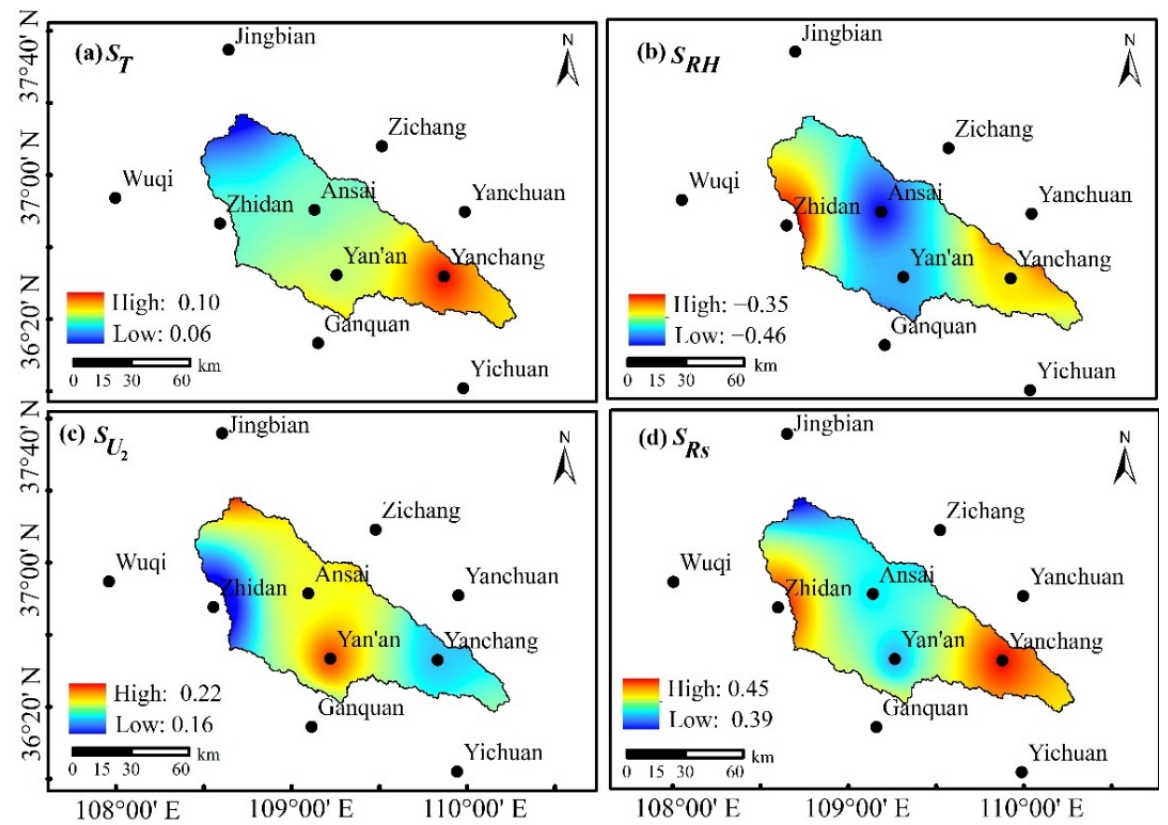

Figure 4. Spatial distribution of sensitivity coefficients of $E T_{0}$ to meteorological factors: (a) air temperature, (b) humidity, (c) wind speed at $2 \mathrm{~m}$ height, (d) solar radiation.

\subsection{Contribution Rate of Meteorological Factors}

On an annual scale, when the $T$ increased by $14.35 \%, E T_{0}$ increased by $1.09 \%$. Since $S_{R H}$ was negative, an increase in $R H$ by $2.09 \%$ led to a decrease in $E T_{0}$ by $0.85 \%$. If $U_{2}$ decreased by $3.24 \%, E T_{0}$ decreased by $0.63 \%$; and when solar radiation increased by $1.32 \%$, $E T_{0}$ increased by $0.55 \%$. Overall, air temperature was the dominant meteorological factor contributing to $E T_{0}$ of the YRB from 1978-2017. From an intra-annual perspective, the increase in air temperature in January and February led to an increase in $E T_{0}$. The increases of $E T_{0}$ in March, July, and August were most strongly correlated with the decrease in $R H$. The observed increase in $E T_{0}$ in April and May was primarily caused by the decrease in $U_{2}$. The most significant driver of $E T_{0}$ in June was solar radiation, and the observed increase in $E T_{0}$ caused by $U_{2}$ nearly offset the decrease driven by lowered $R H$. In September and October, the most significant factor determining lowered $E T_{0}$ was the decline in solar radiation. $T$ was the dominant controlling factor of $E T_{0}$ in November. In November, although $E T_{0}$ had the greatest level of sensitivity to $R H$, its contribution rate was only $0.03 \%$, permitting the inference that the decreasing trend of $R H$ was not the primary cause of the observed decrease in $E T_{0}$. The most significant contribution to $E T_{0}$ in December was $U_{2}$. In December, although $E T_{0}$ was sensitive to $R H$, its decline did not lead to a decrease of $E T_{0}$ (Table 4). 
Table 4. Temporal characteristic of contribution rate of meteorological factors to $E T_{0}$ in Yanhe River Basin.

\begin{tabular}{ccccccccc}
\hline Time & $R_{T} / \%$ & $C_{T} / \%$ & $R_{R H} / \%$ & $C_{R H} / \%$ & $R_{U 2} / \%$ & $C_{U 2} / \%$ & $R_{R S} / \%$ & $C_{R S} / \%$ \\
\hline Jan. & -16.15 & 1.95 & 3.10 & -1.59 & 2.34 & 0.76 & 0.53 & 0.05 \\
Feb. & -123.61 & 6.68 & 8.25 & -3.57 & 0.71 & 0.18 & 1.79 & 0.49 \\
Mar. & 63.48 & 2.86 & -23.68 & 8.61 & -4.53 & -0.92 & 11.87 & 4.79 \\
Apr. & 12.65 & 1.15 & -4.60 & 1.26 & -23.55 & -4.70 & 5.30 & 2.54 \\
May. & 2.77 & 0.33 & -3.47 & 0.88 & -22.31 & -3.66 & 4.09 & 2.31 \\
Jun. & 4.57 & 0.64 & -6.65 & 1.58 & -11.78 & -1.57 & 2.65 & 1.68 \\
Jul. & 6.11 & 1.16 & -5.64 & 1.59 & 3.95 & 0.34 & 2.25 & 1.58 \\
Aug. & 4.48 & 0.96 & -6.40 & 2.09 & 6.20 & 0.43 & -2.29 & -1.60 \\
Sep. & 9.70 & 1.95 & -0.57 & 0.25 & 8.53 & 0.73 & -9.20 & -5.58 \\
Oct. & 11.47 & 1.44 & 4.18 & -2.25 & -5.09 & -0.81 & -6.80 & -2.89 \\
Nov. & 66.20 & 1.26 & -0.04 & 0.03 & -4.10 & -1.17 & -2.04 & -0.33 \\
Dec. & -21.83 & 1.46 & -4.92 & 3.01 & 10.80 & 3.96 & 2.62 & -0.04 \\
Year & 14.35 & 1.09 & 2.09 & -0.85 & -3.24 & -0.63 & 1.32 & 0.55 \\
\hline
\end{tabular}

Across the entire study region, a relatively equal change of a single climatic factor had significantly variable contributions to $E T_{0}$. For example, an increase of $R H$ by $0.74 \%$, lead to a decrease in $E T_{0}$ at the Zichang station by $0.34 \%$, and a decrease at the Yanchang station of $0.24 \%$ (Table 5). Through comparison, it was found that the dominant meteorological factor at Jingbian, Zichang, Ansai, Ganquan, Yanchang, and Yanchuan stations was $U_{2}$. Solar radiation contributed the most to $E T_{0}$ at Wuqi station, and $R H$ was the controlling factor at Zhidan, Yan'an, and Yichuan stations. Air temperature contributed positively to the increase of $E T_{0}$ across the entire basin, whereas the effects of $R H, U_{2}$, and solar radiation on $E T_{0}$ displayed significant spatial variability. For example, the contribution rate of $R H$ to the recorded $E T_{0}$ values of Zichang and Yanchang stations was negative, but all other stations recorded positive rates (Table 5). Because $E T_{0}$ of Zichang and Yanchang stations had a negative sensitivity coefficient to $R H$, the observed increase in $R H$ had a negative effect on $E T_{0}$. Conversely, other sites had a positive effect on $E T_{0}$ due to the decreasing levels of $R H$.

Table 5. Contribution rate of meteorological factors to $E T_{0}$ of stations in Yanhe River Basin.

\begin{tabular}{ccccccccc}
\hline Station & $R_{T} / \%$ & $C_{T} / \%$ & $R_{R H} / \%$ & $C_{R H} / \%$ & $R_{U 2} / \%$ & $C_{U 2} / \%$ & $R_{R S} / \%$ & $C_{R S} / \%$ \\
\hline Jingbian & 27.75 & 2.02 & -9.00 & 3.91 & -31.68 & -6.76 & 2.79 & 1.12 \\
Wuqi & 12.34 & 0.94 & -3.92 & 1.35 & -17.78 & -2.82 & 8.81 & 3.95 \\
Zichang & 16.19 & 1.25 & 0.74 & -0.34 & 10.52 & 2.10 & -0.21 & -0.08 \\
Zhidan & 19.71 & 1.86 & -4.56 & 2.10 & -8.13 & -1.40 & 4.27 & 1.90 \\
Ansai & 11.10 & 0.89 & -1.46 & 0.40 & -18.65 & -3.13 & 2.23 & 0.98 \\
Yan'an & 12.91 & 1.25 & -7.57 & 2.93 & 0.16 & 0.03 & 4.43 & 1.98 \\
Ganquan & 18.00 & 0.54 & -2.99 & 1.37 & -35.71 & -9.16 & -2.18 & -0.74 \\
Yanchuan & 8.27 & 0.54 & -0.51 & 0.18 & 40.06 & 6.90 & -1.17 & -0.50 \\
Yanchang & 4.70 & 0.39 & 0.74 & -0.24 & 34.65 & 6.51 & -3.42 & -1.48 \\
Yichuan & 15.34 & 1.33 & -4.67 & 2.12 & 8.13 & 1.64 & -2.58 & -1.09 \\
\hline
\end{tabular}

Thus, the geographic zonality each meteorological factor's contribution to $E T_{0}$ was significant. The influence of $T$ and solar radiation on $E T_{0}$ gradually decreased from NW to $\mathrm{SE}$ of the basin, whereas $U_{2}$ displayed precisely the opposite pattern. The contribution of $R H$ to $E T_{0}$ decreased radially from Zhidan to the surrounding areas (Figure 5). By combining Figures 2 and 5, it can be ascertained that the high ET in the Yan'an area was primarily driven by $R H$ and solar radiation, whereas the low ET observed in the Zhidan area was mainly affected by $U_{2}$. Because the sensitivity coefficient of $E T_{0}$ to $R H$ in Ganquan was negative, the recorded decrease in $R H$ had a positive effect on $E T_{0}$. Similarly, the sensitivity coefficient of $E T_{0}$ to $U_{2}$ and solar radiation was positive, so the recorded decrease in $U_{2}$ and solar radiation contributed to the observed decrease in $E T_{0}$. Therefore, 
the main factors behind the "evaporation paradox" phenomenon observed in Ganquan were decreasing values of $U_{2}$ and solar radiation.

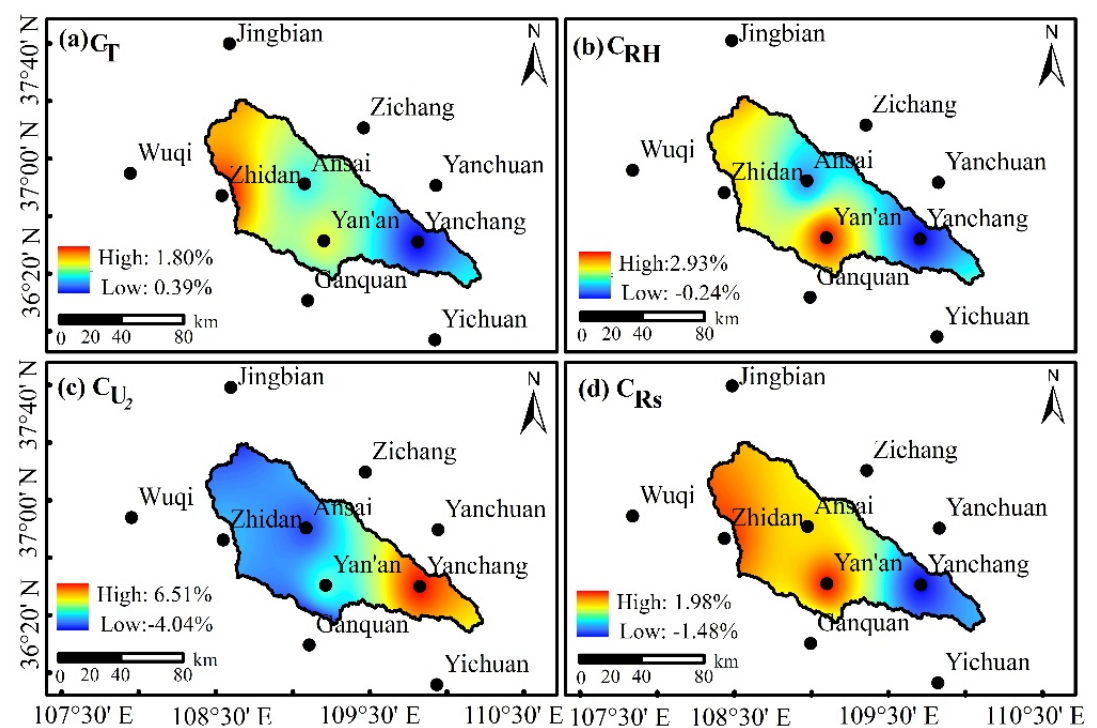

Figure 5. Spatial distribution of contribution rate of each meteorological factor: (a) air temperature, (b) humidity, (c) wind speed at $2 \mathrm{~m}$ height, (d) solar radiation.

\section{Discussion}

Previous studies have found that a combination of the changing meteorological factors, sensitivity coefficients, and contribution rates can more accurately analyze the drivers of $E T_{0}[21,22]$.

\subsection{Dominant Factors of $E T_{0}$ Variation in the $Y R B$}

The calculated absolute values (i.e., strengths) for the sensitivity coefficients of the climatic factors analyzed on $E T_{0}$ were $R s>R H>U_{2}>T$; however, sensitivities varied significantly by month. For example, the sensitivity coefficient of $E T_{0}$ to solar radiation in December was -0.01 , but reached 0.7 in July and August from1978 to 2017. Additionally, the sensitivity coefficient of $T$ in the winter (December, January, February) was negative, but positive throughout the remainder of the year. Combined with the results of trend analysis of meteorological factors, it was found that $T$ still maintained a positive correlation with $E T_{0}$, since $T$ in the winter months was low as well.

The absolute values of the contribution rates for each meteorological factor to $E T_{0}$ were $T>R H>U_{2}>$ solar radiation; and furthermore, these rates for each individual factor varied significantly by month. For example, the contribution rates of $T$ to $E T_{0}$ for January, February, and December were $1.95 \%, 6.68 \%$, and $1.46 \%$, respectively; but these rates in June, July, and August were $0.64 \%, 1.16 \%$, and $0.96 \%$, thus indicating that the contribution of $T$ to the increase of $E T_{0}$ was higher in winter months than in summer. Furthermore, although the sensitivity coefficient of $E T_{0}$ to $T$ was small, its contribution was large as the significantly increasing trends of air temperature $(p<0.01)$ led to an increase of $E T_{0}$. These findings are similar to the results of a study on $E T_{0}$ climate sensitivity coefficients in the Yellow River Basin [15]. In the YRB, although the sensitivity coefficient of $E T_{0}$ to solar radiation was the greatest, its overall contribution to $E T_{0}$ was low due to its relatively stable rate over time.

Combined with precomplaint sensitivity analysis and contribution rate analysis in the present study, it can be seen that only by combining the sensitivity coefficients of changing meteorological factors to $E T_{0}$, can we ascertain their true contribution rates for a more comprehensive understanding of the causes of changes in $E T_{0}$.

In the present study, the multi-year average air temperature of the YRB showed an increasing trend, with a positive sensitivity coefficient, and a contribution rate of $1.09 \%$. 
$R H$ has displayed a decreasing trend with time, a sensitivity coefficient of -0.41 , and contribution rate of $-0.85 \%$. It can be seen, however, that the decreasing trend of $R H$ did not cause the increase in $E T_{0}$ in the YRB. $U_{2}$ also displayed a decreasing trend with time, a positive sensitivity coefficient of $E T_{0}$, and a contribution rate of $-0.63 \%$. Solar radiation showed an increasing trend with time, a positive sensitivity coefficient, and contribution rate of $0.55 \%$. Thus, it can be concluded that the negative contribution rates of meteorological factors $E T_{0}$ were less than the positive. Accordingly, $E T_{0}$ in the YRB has shown an increasing trend from 1978-2017 mostly related to $T, U_{2}$, and solar radiation, whereas observed decreases in $E T_{0}$ were primarily driven by $R H$.

\subsection{Evaporation Paradox in the $Y R B$}

Another pertinent point was that although the $E T_{0}$ of the YRB showed an overall increasing trend, $E T_{0}$ at the Ganquan Station decreased, indicating a sole, local existence of the "evaporation paradox". The absolute value of the sensitivity coefficients for the meteorological factors in the Ganquan area were $R H>$ solar radiation $>U_{2}>T$; and the absolute values of their contribution rates were $U_{2}>R H>$ solar radiation $>T$. In the Ganquan area, the increasing trend of air temperature was significant, but its corresponding contribution rate was relatively low. Solar radiation decreased with time, and its corresponding contribution rate to $E T_{0}$ was $-0.74 \%$, nearly offsetting the positive contribution rate of air temperature. The sensitivity coefficient for $R H$ was -0.46 , with a contribution rate of $1.37 \%$, indicating that the downward trend of $R H$ had a positive effect on $E T_{0}$. Lastly, the sensitivity coefficient for $U_{2}$ was only 0.17 , but its significant downward trend resulted in a contribution rate of $-9.16 \%$, making it the dominant factor driving the observed decreasing trend in $E T_{0}$. This is similar to results found by Roderick \& Farquhar [8], Dinpashoh et al. [12], Burn \& Hesch [10], and Luo et al. [18].

\section{Conclusions}

In this paper, the effects of air temperature $(T)$, relative humidity $(R H)$, wind speed at $2 \mathrm{~m}\left(U_{2}\right)$, and solar radiation on the potential evapotranspiration $\left(E T_{0}\right)$ in the Yanhe River Basin (YRB), China were quantitatively estimated using sensitivity coefficients and contribution rates, combined with the changing trend of meteorological factors observed from 1978-2017. The main conclusions of this study can be summarized as follows:

The absolute value of the sensitivity coefficients of $E T_{0}$ to meteorological factors in the $\mathrm{YRB}$ was solar radiation $>R H>U_{2}>T$, although sensitivities displayed significant temporal (intra- and interannual) and spatial differences. The absolute values of the contribution rates for each meteorological factor were $T>R H>U_{2}>$ solar radiation. Similarly, the contribution rates for the same climatic factors displayed significant spatiotemporal heterogeneity.

The observed increase of $E T_{0}$ in the YRB was related to $T, U_{2}$, and solar radiation; whereas decreases in $E T_{0}$ were mostly related to $R H$. The most dominant factor controlling $E T_{0}$ across the entire YRB was $T$, but this displayed significant spatiotemporal differences at local scales. The "evaporation paradox" phenomenon observed in the Ganquan area was driven primarily by wind speed.

It can be seen from this study only by combining the sensitivity coefficients of changing meteorological factors to $E T_{0}$, with their respective contribution rates, we can systematically and quantitatively analyze the driving mechanisms of observed changes in $E T_{0}$.

Author Contributions: Data curation and writing—original draft preparation, Y.L.; writing—review and editing, and supervision, funding acquisition, P.G. and X.M. Conceptualization, Y.L., P.G. and X.M.; methodology, Y.L., P.G. and X.M.; formal analysis, P.G. and X.M.; resources, Y.L. and P.G.; data curation, Y.L. and P.G.; writing-original draft preparation, Y.L.; writing—review and editing, Y.L., P.G. and X.M.; visualization, Y.L.; supervision, Y.L., P.G. and X.M.; project administration, P.G. and X.M.; funding acquisition, P.G. All authors have read and agreed to the published version of the manuscript. 
Funding: This work was founded by the National Key Research and Development Program of China, Grant/Award Number: 2016YFC0501707.

Institutional Review Board Statement: Not applicable.

Informed Consent Statement: Not applicable.

Data Availability Statement: The daily series of meteorological data used in this study are avaliable on National Meteorological Science Centre of China (http:/ / data.cma.cn/ / (accessed on 28 April 2021)).

Acknowledgments: The authors acknowledge contributions from all members of the project team.

Conflicts of Interest: The authors declare no conflict of interest.

\section{References}

1. IPCC. Summary for Policymakers. In Global Warming of 1.5 C. An IPCC Special Report on the Impacts of Global Warming of 1.5 C Above Pre-Industrial Levels and Related Global Greenhouse Gas Emission Pathways, in the Context of Strengthening the Global Response to the Threat of Climate Change, Sustainable Development, and Efforts to Eradicate Poverty; Masson-Delmotte, V.P., Zhai, H.-O., Pörtner, D., Roberts, J., Skea, P.R., Shukla, A., Pirani, W., Moufouma-Okia, C., Péan, R., Pidcock, S., Eds.; IPCC: Geneva, Switzerland, 2008; in press.

2. Zhou, J. Spatial and Temporal Variation of Droughts Over China Based on Various Potential Evapotranspiration Formulas; Nanjing University of Information Science and Technology: Nanjing, China, 2019.

3. Food and Agriculture Organization of the United Nations. Crop Evapotranspiration: Guidelines for Computing Crop Requirements; Food \& Agriculture Organization: Rome, Italy, 1998.

4. Li, X.C. Spatio-Temporal Variation of Actual Evapotranspiration in the Pearl, Haihe and Tarim Basins of China; Nanjing University of Information Science and Technology: Nanjing, China, 2013.

5. Onyutha, C. Statistical analyses of potential evapotranspiration changes over the period 1930-2012 in the Nile River riparian countries. Agric. For. Meteorol. 2016, 226-227, 80-95. [CrossRef]

6. Cohen, S.; Ianetz, A.; Stanhill, G. Evaporative climate changes at Bet Dagan, Israel, 1964-1998. Agric. For. Meteorol. 2002, 111, 83-91. [CrossRef]

7. Yin, Y.; Wu, S.; Chen, G.; Dai, E. Attribution analyses of potential evapotranspiration changes in China since the 1960s. Theor Appl. Clim. 2010, 101, 19-28. [CrossRef]

8. Roderick, M.L.; Farquhar, G.D. The cause of decreased pan evaporation over the past 50 years. Science 2002, $298,1410-1411$.

9. Roderick, M.L.; Farquhar, G.D. Changes in Australian pan evaporation from 1970 to 2002. Int. J. Clim. 2004, 24, 1077-1090. [CrossRef]

10. Burn, H.D.; Hesch, M.N. Trends in evaporation for the Canadian Prairies. J. Hydrol. 2007, 336, 61-73. [CrossRef]

11. Fu, G.; Charles, S.P.; Yu, J. A critical overview of pan evaporation trends over the last 50 years. Clim. Chang. 2009, 97, 193-214. [CrossRef]

12. Dinpashoh, Y.; Jhajharia, D.; Fakheri-Fard, A.; Singh, V.P.; Kahya, E. Trends in reference crop evapotranspiration over Iran. J. Hydrol. 2011, 399, 422-433. [CrossRef]

13. Chattopadhyay, N.; Hulme, M. Evaporation and potential evapotranspiration in India under conditions of recent and future climate change. Agric. For. Meteorol. 1997, 87, 55-73. [CrossRef]

14. Liu, C.M.; Zhang, D.; Liu, X.M.; Zhao, C.S. Spatial and temporal change in the potential evapotranspiration sensi-tivity to meteorological factors in China (1960-2007). J. Geogr. Sci. 2012, 22. [CrossRef]

15. Liu, Q.; Yang, Z.F.; Cui, B.S.; Sun, T. The temporal trends of reference evapotranspiration and its sensitivity to key meteoro-logical variables in the Yellow River Basin, China. Hydrol. Process. 2010, 24, 2171-2181.

16. Gong, L.B.; Xu, C.Y.; Chen, D.L.; Halldin, S.; Chen, Y.Q. Sensitivity of the Penman-Monteith reference evapotranspi-ration to key climatic variables in the Changjiang (Yangtze River) basin. J. Hydrol. Amst. 2006, 329, 620-629. [CrossRef]

17. Wang, Y.; Jiang, T.; Bothe, O.; Fraedrich, K. Changes of pan evaporation and reference evapotranspiration in the Yangtze River basin. Theor. Appl. Clim. 2006, 90, 13-23. [CrossRef]

18. Luo, K.; Tao, F.; Deng, X.; Moiwo, J.P. Changes in potential evapotranspiration and surface runoff in $1981-2010$ and the driving factors in Upper Heihe River Basin in Northwest China. Hydrol. Process. 2016, 31, 90-103. [CrossRef]

19. Zhang, Y.Q.; Liu, C.M.; Tang, Y.H.; Yang, Y.H. Trends in pan evaporation and reference and actual evapotran-spiration across the Tibetan Plateau. J. Geophys. Res. Atmos. 2007, 112. [CrossRef]

20. Li, Z.; Zheng, F.L.; Liu, W.Z. Spatiotemporal characteristics of reference evapotranspiration during 1961-2009 and its pro-jected changes during 2011-2099 on the Loess Plateau of China. Agricultural E Forest Meteorology; Elsevier: Amsterdam, The Netherlands, 2012; Volume 154, pp. 147-155.

21. Liu, X.M.; Zheng, H.X.; Liu, C.M.; Cao, Y.J. Sensitivity of the potential evapotranspiration to key climatic variables in the Haihe River Basin. Resour. Sci. 2009, 31, 1470-1476. 
22. Su, X.L.; Song, Y.; Niu, J.P.; Ji, F. Sensitivity and attribution of potential evapotranspiration in Jinghuiqu irrigation district. J. Nat. Resour. 2015, 1, 115-123.

23. Yang, X.N. Effects of Landscape Pattern on Runoff Andsediment in the Loess Plateau: A Multi-Scale Study; Ph.D. Thesis, Northwest A \& F University: Xianyang, China, 2019.

24. Jiao, J.Y.; Wang, Z.J.; Wei, Y.H.; Su, Y.; Cao, B.T.; Li, Y.J. Characteristics of erosion sediment yield with extreme rainstorms in Yanhe Watershed based on field. Trans. Chin. Soc. Agric. Eng. 2017, 33, 159-167.

25. Zhang, X.L.; Xiong, L.H.; Lin, L.; Long, H.F. Application of five potential evapotranspiration equations in Hanjiang Basin. Arid. Land Geogr. 2012, 35, 229-237.

26. McCuen, R.H. A Sensitivity and Error Analysis Cf Procedures Used for Estimating Evaporation. JAWRA J. Am. Water Resour. Assoc. 1974, 10, 486-497. [CrossRef]

27. Beven, K. A sensitivity analysis of the Penman-Monteith actual evapotranspiration estimates. J. Hydrol. 1979, 44, 169-190. [CrossRef]

28. Rana, G.; Katerji, N. A Measurement Based Sensitivity Analysis of the Penman-Monteith Actual Evapotranspiration Model for Crops of Different Height and in Contrasting Water Status. Theor. Appl. Clim. 1998, 60, 141-149. [CrossRef]

29. Hupet, F.; Vanclooster, M. Effect of the sampling frequency of meteorological variables on the estimation of the reference evapotranspiration. J. Hydrol. 2001, 243, 192-204. [CrossRef]

30. Mann, H.B. Non-Parametric Test against Trend. Econometrica 1945, 13, 245-259. [CrossRef]

31. Kendall, M.G. Rank Correlation Measures; Charles Griffin: London, UK, 1975; p. 202.

32. Lin, Z.H.; Mo, X.G.; Li, H.X.; Li, H.B. Comparison of Three Spatial Interpolation Methods for Climate Variables in China. Acta Geogr. Sin. 2002, 57, 47-56. 